\title{
Communication
}

\section{Integrating Ecological Assessments to Target Priority Restoration Areas: A Case Study in the Pearl River Delta Urban Agglomeration, China}

\author{
Xinchuang Chen ${ }^{1,2}$, Feng $\mathrm{Li}^{3, *}$, Xiaoqian $\mathrm{Li}^{1,2}$, Hongxiao Liu ${ }^{4}$, Yinhong $\mathrm{Hu}{ }^{1,2}$ and Panpan $\mathrm{Hu}{ }^{1,2}$ \\ 1 State Key Laboratory of Urban and Regional Ecology, Research Center for Eco-Environmental Sciences, \\ Chinese Academy of Sciences, Beijing 100085, China; xcchen_st@rcees.ac.cn (X.C.); xqli_st@rcees.ac.cn (X.L.); \\ yhu63@jh.edu (Y.H.); pphu_st@rcees.ac.cn (P.H.) \\ 2 University of Chinese Academy of Sciences, Beijing 100049, China \\ 3 School of Architecture, Tsinghua University, Beijing 100084, China \\ 4 South China Botanical Garden, Chinese Academy of Sciences, Guangzhou 510650, China; liuhx@scbg.ac.cn \\ * Correspondence: feng_li@tsinghua.edu.cn
}

check for

updates

Citation: Chen, X.; Li, F.; Li, X.; Liu, H.; Hu, Y.; Hu, P. Integrating Ecological Assessments to Target Priority Restoration Areas: A Case Study in the Pearl River Delta Urban Agglomeration, China. Remote Sens. 2021, 13, 2424. https://doi.org/ $10.3390 /$ rs13122424

Academic Editor: Maria

Laura Carranza

Received: 7 May 2021

Accepted: 19 June 2021

Published: 21 June 2021

Publisher's Note: MDPI stays neutral with regard to jurisdictional claims in published maps and institutional affiliations.

Copyright: (c) 2021 by the authors. Licensee MDPI, Basel, Switzerland. This article is an open access article distributed under the terms and conditions of the Creative Commons Attribution (CC BY) license (https:/ / creativecommons.org/licenses/by/ $4.0 /)$.

\begin{abstract}
The identification and management of ecological restoration areas play important roles in promoting sustainable urban development. However, current research lacks a scientific basis for the scope and scale of ecological restoration. Further, the absence of a framework to assess policy goals and public preferences that leads to identification of ecological restoration areas across the science-policy interface is difficult, and the existing frameworks' performance has little applicability. We proposed a transdisciplinary framework to combine ecological quality, ecological health, and ecosystem services as an assessment endpoint to identify priority restoration areas. Further, we classified the ecological restoration areas on a township scale by K-means. Based upon policy goals and public preferences of the Pearl River Delta urban agglomeration, we chose air quality, biodiversity, soil fragility, recreation quality, ecosystem vigor, landscape metrics, and the water supply ecosystem service as elements of the evaluation system. This study showed that priority restoration areas accounted for $10.8 \%$ of the urban agglomeration area and classified township, largely in the difference between natural and semi-natural ecosystems and the human environment. Policymakers can use this framework comprehensively and flexibly to identify and classify ecological restoration areas to achieve policy goals and fulfil public preferences.
\end{abstract}

Keywords: ecological space; ecological quality; ecological health; ecological restoration; Pearl River Delta urban agglomeration

\section{Introduction}

Human activities have significant adverse effects on the regional ecological environment that result in climate change, loss of biodiversity, and ecosystem degradation [1]. In developing countries in particular, urbanization has resulted in changes in land use, encroachment on ecological areas, and destruction of primitive habitats [2], all of which have led to the decline in regional ecosystems' quality and health, and varying degrees of degeneration. Approximately 2 billion hectares of the world's terrestrial ecosystems are considered degraded and in need of ecological restoration $[3,4]$. These ecosystems' decrease in area and widespread degradation has reduced ecosystem services and increased ecological risk [5]. With the promotion of sustainable urban development, the ecosystem's protection and restoration have become prominent research topics that focus on assessing ecosystem services for urban planning [6-8]. Assessing ecological space is dominated largely by social and economic activities, particularly policy-oriented and decision-making needs $[9,10]$. Thus, comprehensive research on the application of scientific assessment of ecological space to help make decisions and policies should be strengthened [11,12]. 
Evaluation of ecological space in environmental science and policy formulation has become increasingly prominent. Mapping ecological space through remote sensing can show decision-makers the imbalance in ecological development intuitively and strengthen the integrated management of regional ecological space [13]. For example, China's Ecological Redline Policy is one of the first national policies on the application of mapping ecological space in spatial scale, which has been established as a core ecological function in ecological protection [14]. Ecological management is concentrated primarily in areas with high ecological quality or high risk [15]. The absence of management of other ecological spaces, particularly ecological restoration space, reduces the region's total ecosystem services $[16,17]$. At present, urban planning and ecological management are facing the challenge of balancing current human needs and maintaining the ecological capacity of future generations [18]. Current research and ecological management should focus more on restoring ecological space within the limited space of a city. The goal should be to improve the ecological space's quality and security and ensure that it does not degenerate [13]. Thus, it is necessary to establish an interdisciplinary assessment framework to identify priority restoration areas based on remote sensing data $[19,20]$.

Mapping ecological restoration areas are increasingly used for supporting decisions in land-use planning [21]. Approaches that combine remote sensing information, vegetative cover, landscape data, and field measurements for mapping ecological restoration have been demonstrated to capture the location and change of ecological restoration areas [22]. At present, the research on mapping ecological restoration areas was still in its infancy, mainly including the ecological security pattern, the tradeoffs between supply and demand based on ecosystem services, and the establishment of a comprehensive index system [23]. The index system is mainly reflected ecological quality, ecological health, and ecosystem services [24,25]. Ecological quality is the ecosystem's external state and an index for residents to perception the living environment's quality directly, and is also the principal manifestation of policy objectives [13]. Ecological health reflects the ecosystem's stability under pressure, which is the core element in identifying ecological damage [25]. Assessment of ecological health emphasizes ecosystems' integrity and provides foundations to assess ecosystem damage. In evaluating ecological quality and health, it is helpful to discriminate the spatiotemporal characteristics of ecosystem functions and ecological security, as well as identify the priority areas that need to be restored $[3,26]$. Ecological quality and health can be used as the evaluation endpoints that connect the ecological process and the identification of ecological restoration areas. At present, there is a lack of research on ways to integrate ecological quality and health into the spatial assessment system used to identify ecological restoration areas, largely because the selection of evaluation indicators lacks a scientific basis and applicability.

The selection of evaluation indicators should meet not only policymakers' policy goals but also the public's and stakeholders' needs. This study used both questionnaire and field surveys to construct an evaluation framework by developing ecological quality and ecological health indices with which decision-makers, stakeholders, the public, experts, and policy goals are concerned. We used the Pearl River Delta (PRD) urban agglomeration as a case study, which is one of the most developed, densely populated, and highly urbanized areas in China [27]. Our goals were to: (1) Construct a framework to identify priority ecological restoration areas based upon the combination of ecological quality and health; (2) perform a cluster analysis of the restoration areas' ecological indices and identify ecological restoration bundles, and (3) explore the characteristics of ecological restoration bundles and offer suggestions for ecological management. In doing so, we proposed a multidisciplinary framework to identify ecological restoration areas spatially. The identification and classification of restoration areas are highly important to the sustainable development of urban agglomerations. This study promoted the applicability of ecological assessment and ecological management to cope with the complexity and variability of the real world. 


\section{Materials and Methods}

\subsection{Study Area}

The PRD urban agglomeration located in southern Guangdong province, China, consisting mainly of nine cities: Guangzhou (GZ), Dongguan (DG), Shenzhen (SZ), Huizhou (HZ), Foshan (FS), Zhongshan (ZS), Zhuhai (ZH), Jiangmen (JM), and Zhaoqing (ZQ) (Figure 1a). The PRD covered an area of $54,770 \mathrm{~km}^{2}$ inhabited by approximately 63 million people in 2018 (Statistical yearbook of Guangdong Province). With the rapid development of urbanization, the ecological problems and ecological risks were increasing significantly, and regional ecological security was facing certain threats [7]. The PRD is currently concerned with important ecological restoration planning issues, with a political leadership assuming the ambition to reach sustainable development by 2035 . To reach this objective, the most important thing is to identify the ecological restoration area and implement ecological restoration zoning and hierarchical control. Currently, policymakers need more information about ecological restoration targets and ecological restoration locations to achieve policy goals. A major challenge is developing capacities on ecological restoration identification for urban planning, which is difficult because ecological assessment requires new interdisciplinary methodologies to assess multiple ecological space and social concerns.

Ecological space is a collection of natural, artificial, and semi-artificial ecological units [28]. Regions that play an important role in the ecosystem can be regarded as ecological spaces. They include not only forestland, grassland, wetland, water bodies, and other natural ecological spaces, but also cropland, parks, ecological corridors, and other areas that provide ecosystem services $[13,29]$. According to the definition of ecological space and land use data, the ecological space in this paper was divided into five broad types: forest land, cropland, grassland, water, and unused land [13] (Figure 1b). The ecological space data were derived from the Resource and Environment Science Data Center of the Chinese Academy of Sciences (http:/ / www.resdc.cn/, accessed on 13 June 2020), with a spatial resolution of $30 \mathrm{~m}$. Landsat 8 remote sensing images were used as data sources to interpret ecological space data obtained in 2018. Through random sampling inspections, the accuracy rates of land-use classifications were greater than 94\% (Table S1), which can be used to explain the land changes [10,27].
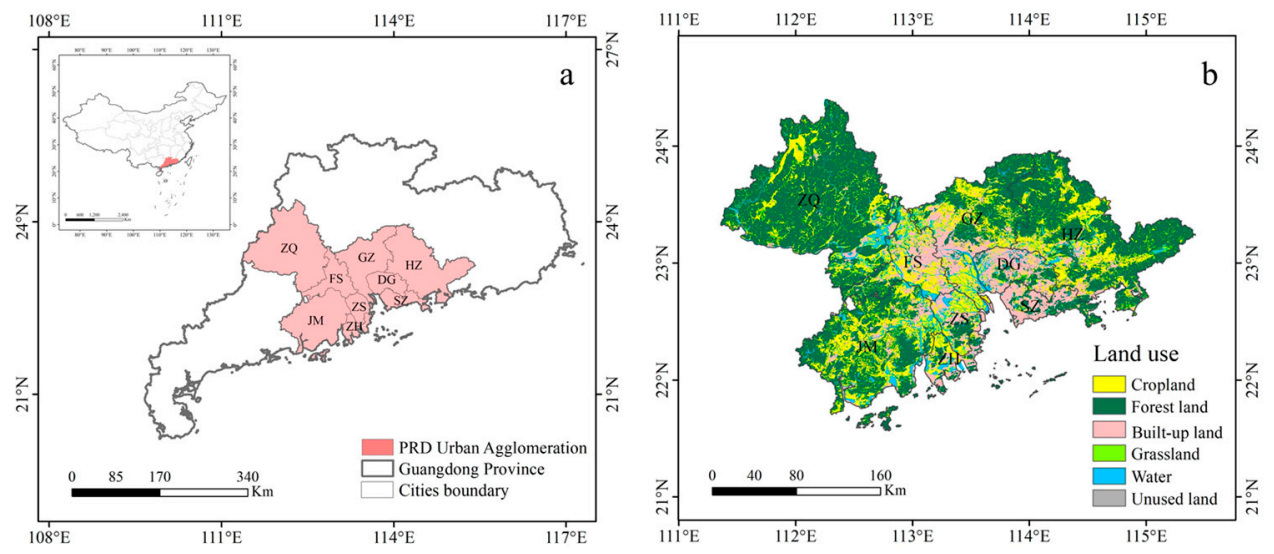

Figure 1. Location of the Pearl River Delta (PRD) urban agglomeration in China (a) and its land-use of PRD urban agglomeration in 2018 (b). DG: Dongguan, FS: Foshan, GZ: Guangzhou, HZ: Huizhou, JM: Jiangmen, SZ: Shenzhen, ZH: Zhuhai, ZQ: Zhaoqing, and ZS: Zhongshan.

\subsection{Selection of Ecological Quality and Ecological Health Indicators}

Ecological restoration is the result of multiple trade-offs. Ecological restoration areas have been defined as land that has experienced persistent decline or loss in biodiversity and ecosystem functions and services that cannot recover fully unaided within decadal time scales [30,31]. Considering the sustainable development of cities, this study defined ecological restoration areas as low-quality or high-risk areas, which represent lower values 
of regional biodiversity, ecosystem functions, and services that needed to be improved [32]. The assessment indicators should be selected based upon differing knowledge systems, such as policy goals, public preferences, expert knowledge, environmental quality, and successful restoration engineering [33,34]. The ecological goals of urban agglomeration planning and environmental protection planning are described in such documents as the "Planning for restoration of land in Guangdong (2020-2035)". This proposes to divide ecological space with important ecological functions or fragile ecosystems or natural ecological protection into an important ecological management space. "The Development planning of the Guangdong-Hong Kong-Macao Greater Bay Area" suggested further that urban planning should guarantee water resources' safety, and build ecological corridor and biodiversity protection networks. The policy goals were to maintain the natural ecosystems' integrity and health as a starting point, expand high-quality ecological areas, and safeguard the human environment's health and safety. Based upon this, the methodology adopted was based on participatory workshops involving policymakers and researchers. All of them have a good knowledge of the study area and the ecological restoration, through their involvement in field-based research or restoration activities. We found that policymakers and researchers hope to enhance biodiversity, air quality, water supply, public environmental health, and regional ecological security through the restoration of ecological space. To meet these requirement, ecological quality and health were integrated to represent the policy goals and public preferences to identify the ecological restoration areas (Figure 2) and then identify the imbalance in regional ecological development and analyze the ecological areas that need restoration to meet policy goals and public preferences. These requirements may be met by selecting hotspot areas of ecological quality and health [14]. Incorporating the different types of hotspots into spatial planning can help policymakers draft more comprehensive strategies to improve the ways to balance environmental protection and urban development $[14,35]$. In this study, policy objectives, expert knowledge, and public preferences were combined to determine the choice of hotspots. Ecological areas that ranked as those that provided less than $10 \%$ of ecological quality and health were prioritized as ecological restoration areas.

\subsection{Selection and Calculation of Ecological Quality Indicators}

We identified a preliminary assessment index system based on participatory workshops. Then, questionnaires were administered to the residents of the PRD urban agglomeration to determine their preferences for the ecological space. We asked the respondents what kind of ecological qualities concern them generally (Select at least one item or choose three items at most): (1) Biodiversity; (2) vegetation coverage; (3) water network density; (4) river water quality; (5) soil fragility; (6) air quality; (7) outdoor recreation quality; (8) landscape connectivity, and (9) other. Random sampling was used in the survey. A total of 500 questionnaires were distributed, and 361 valid questionnaires were collected, including 204 questionnaires in the urban community and 157 questionnaires in the rural community (Table S2). Respondents mainly included farmers, employees, retirees, and whose preferences cover all or part of the urban agglomeration. More than $50 \%$ of respondents preferred biodiversity $(B D)$, outdoor recreation quality $(O R)$, air quality $(A Q)$, and soil fragility (SF) (Figure S1). This reflected residents and stakeholders focused largely on meeting their leisure and recreational needs, as well as maintaining a good living and working environment with forest coverage, high air quality, and park accessibility. Finally, these indices were selected as ecological space quality $(E Q)$ assessment indicators, and the weight of each was determined according to the Analytic Hierarchy Process. The calculation formula was as follows:

$$
E Q=0.3 \times B D+0.25 \times A Q+0.25 \times O R+0.2 \times S F
$$




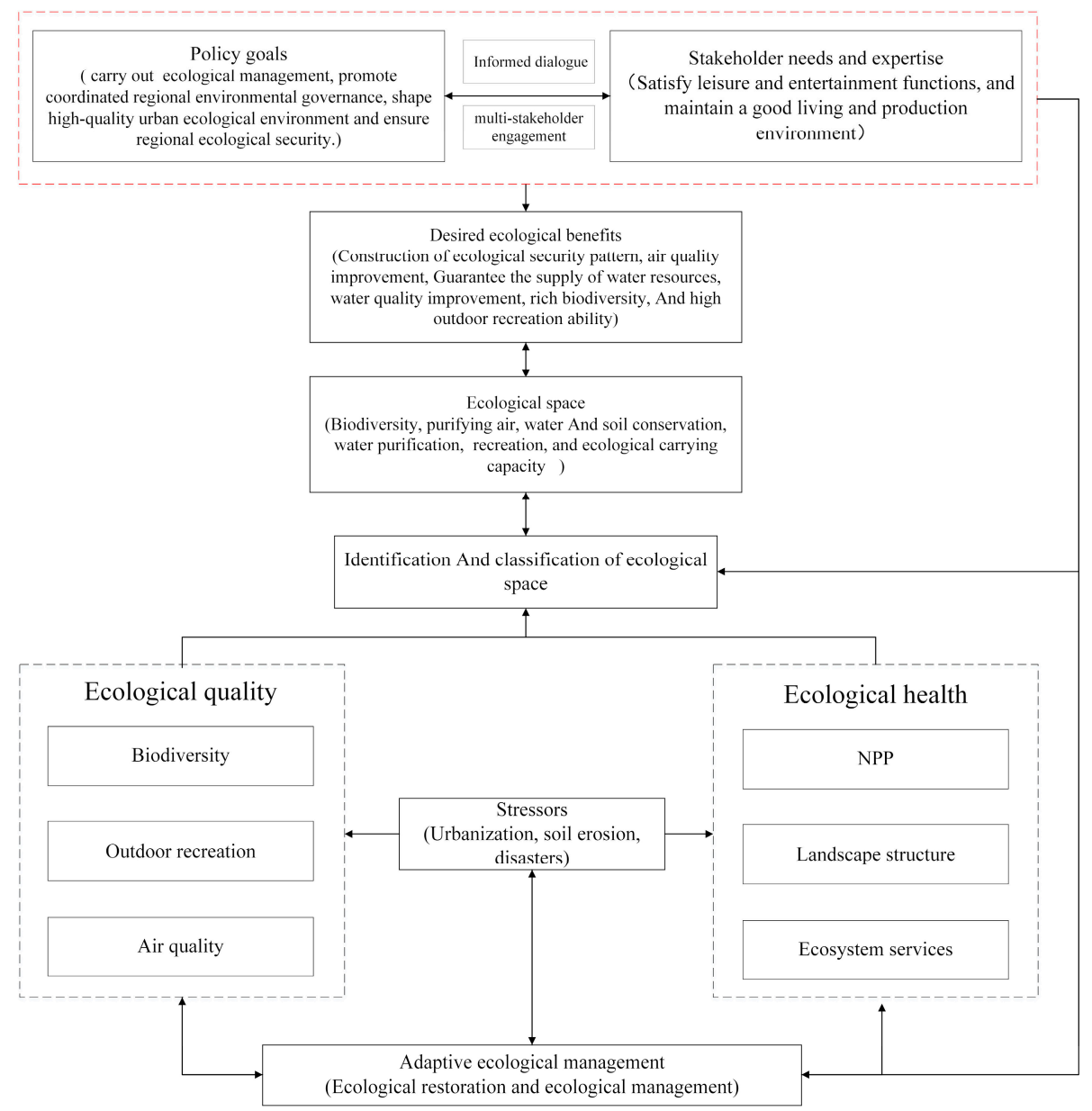

Figure 2. A multi-disciplinary framework to identify ecological restoration areas by linking policy and ecological information. Identification of ecological restoration areas depends upon their ecological quality and health (black dotted bordered rectangle). The assessment of ecological quality and health should incorporate policy goals, local stakeholder needs, and expert knowledge (red dotted bordered rectangle) to select the desired index to ground the analysis in the given decision-making context to achieve equal and full representation. NPP: Net primary productivity.

In view of the experimental data's availability and spatial representation, this study referred to previous studies [13] that established the basic equivalent of different types of ecosystem service functions' value based upon expert experience to determine the land use types' biodiversity (Table S3). The air quality index derived from the Environmental Data Center of the Ministry of Environmental Protection of China (http:/ / datacenter.mep. gov.cn, accessed on 5 April 2019). The ESTIMAP-recreation method was adopted for residents' outdoor recreation [36]. The score of each grid was calculated by summing three components (degree of naturalness, nature protection, and water) (Table S4). The soil fragility index was weighted by soil erosion using the Ministry of Environmental Protection of China's habitat quality index as the standard. Soil erosion originated from the Resource and Environment Science Data Center of the Chinese Academy of Sciences (http://www.resdc.cn/, accessed on 17 March 2019) (Table S5). The indices were all normalized to 0-100 according to their positive or negative effects.

\subsection{Selection and Calculation of Ecological Health Indicators}

The selection of ecological health indicators was based upon the ecosystem's ability to maintain a healthy structure, self-regulate, and recover under pressure, and was characterized synthetically by vigor, organization, and resilience [25]. Vigor represents the ecosystem's primary productivity. In this study, net primary productivity (NPP) 
was used to evaluate ecosystem vigor, and NPP data (MOD17A3) were acquired from http:/ /ladswed.nascom.nasa.gov [37], accessed on 8 December 2019. The organization was determined primarily by landscape pattern [18], landscape connectivity, landscape heterogeneity, forest land, and wetland landscape characteristics that were characterized synthetically; their weight was determined according to previous studies [25].

$$
\begin{aligned}
\mathrm{O}= & 0.1 \times \mathrm{AWMPFD}+0.25 \times F N_{1}+0.15 \times \mathrm{SHDI}+0.1 \times \mathrm{MSIDI}+0.1 \times \mathrm{CONT} \\
& +0.1 \times F N_{2}+0.05 \times \mathrm{CONNECT}_{1}+0.1 \times F N_{3}+0.05 \times \mathrm{CONNECT}_{2},
\end{aligned}
$$

in which $O$ is ecosystem organization, AWMPFD is the index of the area-weighted mean patch fractal dimension, $F N_{1}$ is landscape fragmentation index, SHDI is Shannon's diversity index, MSIDI is modified Simpson's diversity index, CONT is the landscape contagion index, $F N_{2}$ is the fragmentation index of forest land, $\mathrm{CONNECT}_{1}$ is the index of the patch connect of forest land, $F N_{3}$ is the fragmentation index of wetland, and $\mathrm{CONNECT}_{2}$ is the index of the patch connect of wetland. These indicators were obtained using the moving window method in Fragstats v. 4.2 (the University of Massachusetts); the landscape index ranges from 0 to 100 , and the unit is the percentage.

Ecosystem resilience refers to the regional ecosystem's ability to restore itself to its original structure and function after external disturbance. This was determined largely by service indicators that regulate ecosystems' important ecological processes and functions [38]. In this study, the ecosystem services' regulatory services were used to represent the policy objectives of the water supply's resilience, which reflected the ecosystem's ability to conserve water, the most important ecosystem service in the PRD. The ecosystem service indicators above were calculated using the InVEST v. 3.3.3 model [14,39].

\subsection{Identification of Management Bundles via a K-Means Cluster Analysis}

Classifying ecological restoration areas helps identify different types of restrictive ecological elements in the areas and furthers the implementation of ecological management measures. Through a trade-off and synergistic analysis, air quality was found to be correlated significantly only with resilience. Based upon this, we eliminated the air quality index in the selection of classification indices of ecological restoration areas. To formulate the ecological policy and manage the ecological space for policymakers, we took the township as the statistical unit. To identify ecological restoration bundles, we selected the K-means clustering consistent with other similar studies [17,40]. Thereafter, we used the $\mathrm{NbClust}$ package in the R statistical software (v. 4.0.3) to choose the optimal number of K-means clusters [41,42].

\section{Results}

\subsection{Spatial Identification of Ecological Restoration Areas}

Incorporating the different types of hotspots into spatial planning can help policymakers draft more comprehensive strategies to balance environmental protection and urban development. Ecological areas that demonstrated the lower $10 \%$ of ecological quality and health were identified as restoration hotspots (Figure 3). By choosing the hotspot areas according to ecological space quality, a land area of $3692.5 \mathrm{~km}^{2}$ was selected as the ecological quality hotspot, which was distributed primarily in the cropland that accounted for $99.5 \%$ of the built-up land (Figure 4a). A land area of $2632.7 \mathrm{~km}^{2}$ was selected as the ecological health hotspot, which was distributed largely in cropland and water bodies (mainly ponds) and accounted for $52.7 \%$ of the area (Figure $4 \mathrm{~b}$ ). Finally, we superimposed the ecological quality and health hotspots synthetically, excluding $436.9 \mathrm{~km}^{2}$ of overlapping areas, and the potential ecological restoration areas totaled approximately $5888.3 \mathrm{~km}^{2}$ that accounted for $10.8 \%$ of the PRD's urban agglomeration area (Figure 4c). With respect to the total amount, the restoration areas were concentrated primarily in ZQ, FS, and HZ. However, in terms of unit area, the restoration areas were concentrated in FS (Figure 4d). 


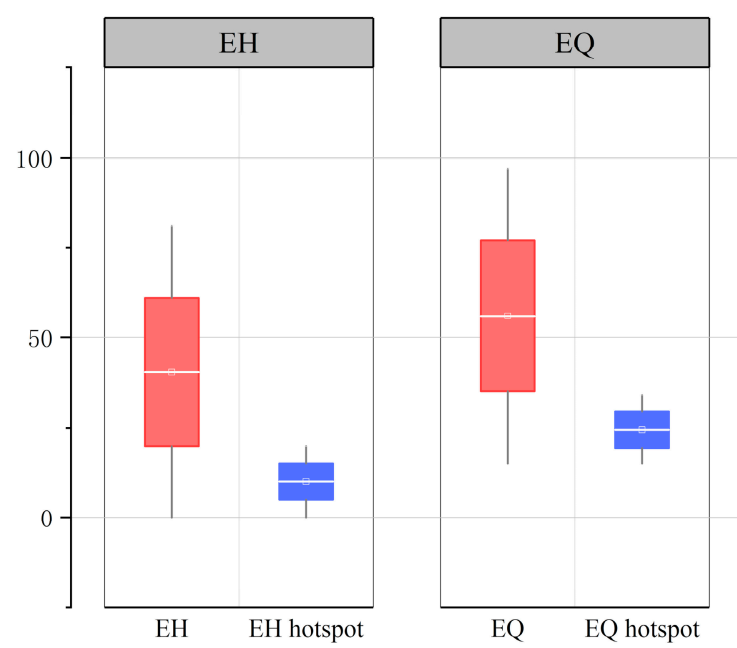

Figure 3. Evaluation of hotspot indicators. We use a 10\% threshold for ecological quality (EQ) and ecological health (EH). The total range of ecological quality and ecological health (shown in hyacinth) relative to hotspots (shown in blue).

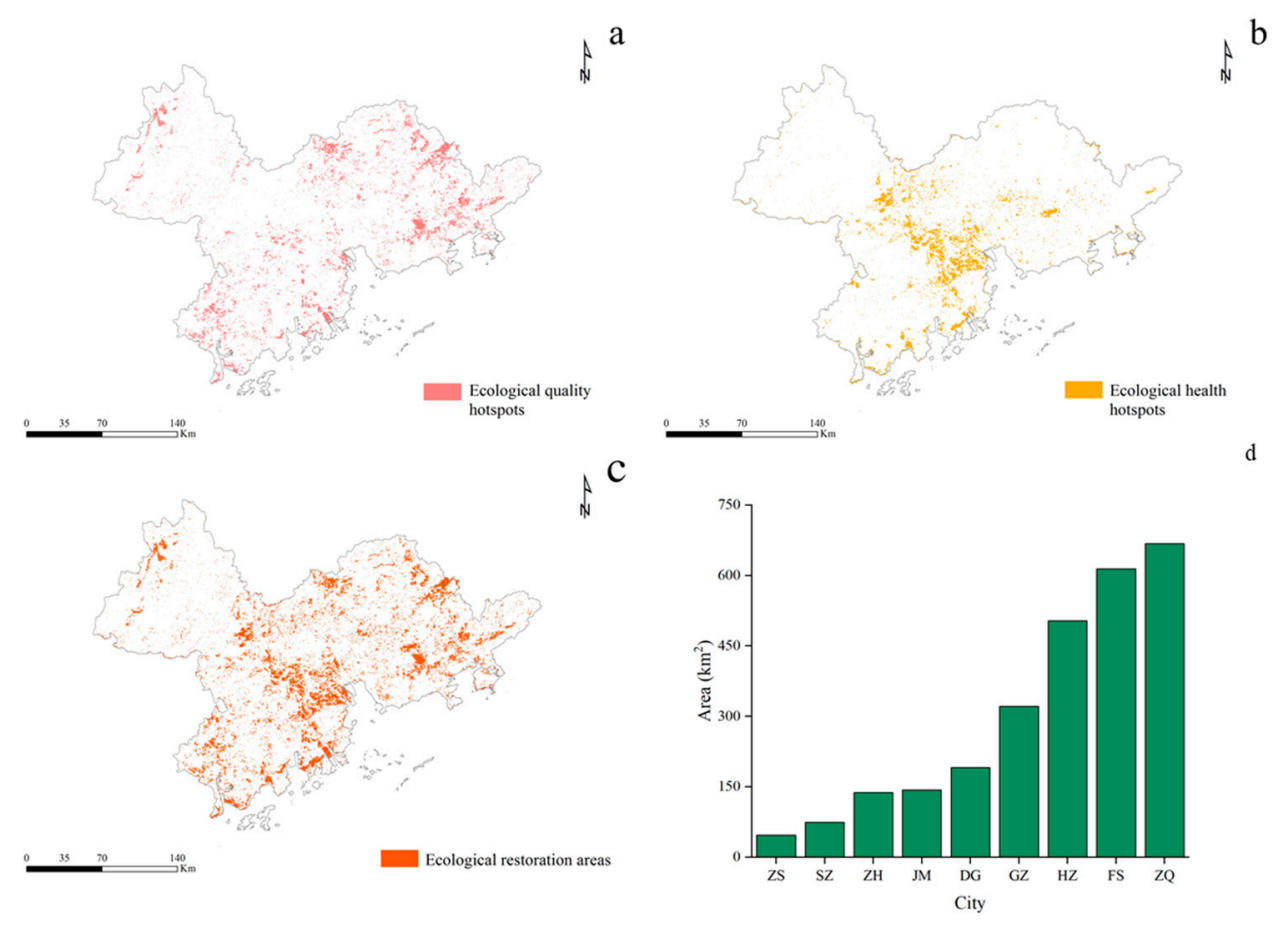

Figure 4. Spatial results for the ecological hotspots and ecological restoration areas. (a) Ecological space quality hotspots; (b) ecological health hotspots; (c) ecological restoration areas, and (d) ecological restoration area in the city of the Pearl River Delta urban agglomeration.

\subsection{Classification of Township Management in Ecological Restoration Areas}

This study adopted the K-means algorithm to classify the indicators into five categories (Figure 5), and then explained them according to land classification characteristics, and the characteristics of leading ecological indicators (Table 1). Land use types can respond directly to policies and socioeconomic effects, which is the core of ecological management [6,43]. Bundle 1 (34.6\% of the restoration area, 32.7\% of the urban agglomeration area) consisted largely of forestland (59.6\%) and cropland (25.1\%). The regional ecological indicators were relatively balanced, but the values were low. The regional human activities were primarily agriculture-based and low-level, and were found in the primary agricultural economic region. Bundle 2 (11.4\% of the restoration area, 31.2\% of the urban agglomeration 
area) was composed mainly of large areas of natural forestland (84.6\%). It had a high ecosystem service function and was an important area in which to construct a regional ecological security pattern. The ecological restoration area was distributed largely around cropland and forestland. Bundles 1 and 2 were largely natural ecosystems with high quality ecological space and low health risk, and were the main areas of regional ecosystem services (supply and regulation). This study found that the areas that require ecological restoration were concentrated largely in the border areas between cropland and forestland. The main cause of regional degradation was the fact that, because of new agricultural activities, cropland had invaded natural ecological space. The ecological management policies should strengthen the protection of forestland, improve existing croplands' quality, convert cropland to forestland and grassland, and establish nature reserves and ecological recreational areas to enhance the regional outdoor recreational capacity. Bundle 3 (32.5\% of the restoration area, $21.4 \%$ of the urban agglomeration area) consisted primarily of cropland $(38.4 \%)$ and built-up land $(20.8 \%)$. This area had little urbanization and a high level of agriculture. Except for organization, the other indicators in this bundle were lower than the average value, which was the key restoration area in the region. Bundle 3 was primarily a semi-natural ecosystem found in an area with little urbanization. It was the main area in which agriculture was distributed in the urban agglomeration and also the focus of regional ecological restoration. It is necessary to adjust the agricultural planting structure, transform "simple" crops into agroforestry systems, and integrate natural processes into agricultural production. Given the regional ecological characteristics, it is recommended to build fishponds with appropriate regional characteristics. Ponds function to regulate the amount of water and increase water quality [39]. The government can consider implementing ecological compensation to encourage this practice. Bundle 4 (3.5\% of the restoration area, $1.6 \%$ of the urban agglomeration area) consisted largely of water bodies (37.8\%) and cropland (29\%). It was distributed primarily along the coast of the Pearl River and around the reservoir, and had high outdoor recreational potential. Bundle 4 was a special area of the PRD urban agglomeration that was composed primarily of rivers and reservoirs. It has a dense river network and is a good place for outdoor recreation. However, in identifying ecological restoration areas, it was found that this area also faces encroachment by cropland or built-up land. The government should implement measures to convert cropland to water bodies and expand the water surface area, as well as engage in greening to enhance the opportunities for recreation and leisure. Particularly in the case of ponds, ecological management should change their main service from aquaculture to leisure tourism, carry out greening and beautification, enhance biodiversity, and develop ecological tourism, such as fishing, moderately. Bundle 5 (18\% of the restoration area, $13.1 \%$ of the agglomeration area) was composed primarily of built-up land (39.2\%) and cropland (23\%) distributed in the central part of the PRD urban agglomeration in a highly urbanized area. Bundle 5 is related closely to highly urbanized areas where the expansion of urban built-up land is the main threat to the ecological space and the intensive change in land use and increased population density has led to the decline in ecosystem services and ecological health. Hence, ecological management should rely upon the PRD's good river network structure and traffic trunk lines, select appropriate local, rather than exotic plant species, build ecological corridors, small urban green spaces, diversified natural ecological spaces, and enhance the urban ecological space's outdoor leisure capacity. 


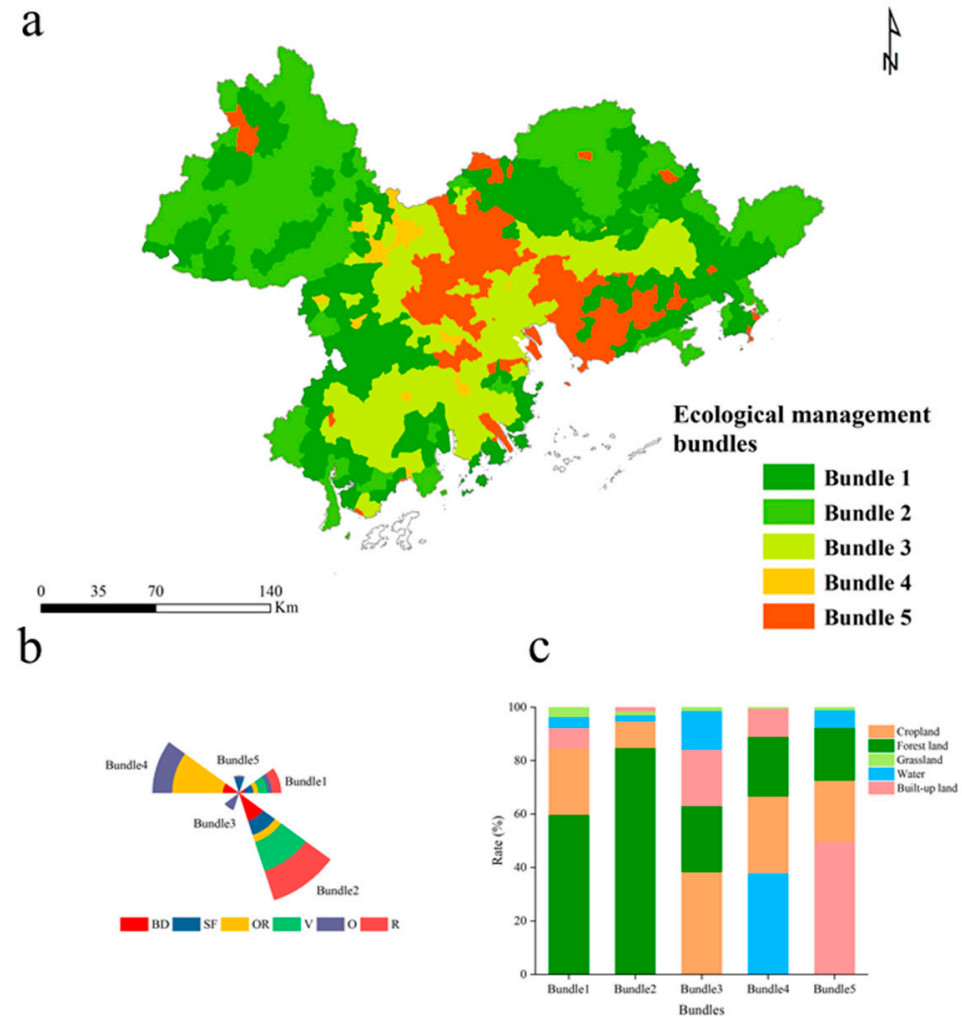

Figure 5. The ecological management bundles based upon ecological restoration. (a) The spatial distribution characteristics of the ecological management bundle, (b) the ecological indices of ecological management bundles. Data were standardized to facilitate comparison among ecological indices. The length of each box is proportional to the relative abundance of the other ecological indices within each bundle. BD: biodiversity; SF: soil fragility; OR: outdoor recreation quality; V: vigor; O: organization; R: resilience, (c), The land-use types of ecological management bundles.

Table 1. The description information of ecological restoration bundles.

\begin{tabular}{|c|c|c|c|}
\hline & Main Land Use Types & Main Ecological Pressures & $\begin{array}{c}\text { Main Ecological Restoration and Ecological } \\
\text { Management }\end{array}$ \\
\hline Bundle 1 & Forestland and Cropland & $\begin{array}{l}\text { Cropland and built-up land } \\
\text { encroach on forest land }\end{array}$ & $\begin{array}{l}\text { Strengthen the protection of forestland; } \\
\text { Improve existing croplands' quality; } \\
\text { Establish ecological recreational areas. }\end{array}$ \\
\hline Bundle 2 & Forestland & $\begin{array}{l}\text { Cropland encroaches on } \\
\text { forest land }\end{array}$ & $\begin{array}{c}\text { Strengthen the protection and construction of } \\
\text { forestland; } \\
\text { Convert cropland to forestland and grassland; } \\
\text { Establish nature reserves. }\end{array}$ \\
\hline Bundle 3 & $\begin{array}{l}\text { Cropland and built-up } \\
\text { land }\end{array}$ & $\begin{array}{l}\text { Built-up land encroaches on } \\
\text { cropland }\end{array}$ & $\begin{array}{l}\text { Ensure quantity and quality of essential cropland; } \\
\text { Adjust the agricultural planting structure, } \\
\text { transform 'simple' crops into agroforestry systems; } \\
\text { Integrate natural processes into } \\
\text { agricultural production. }\end{array}$ \\
\hline Bundle 4 & Water bodies and cropland & $\begin{array}{l}\text { Built-up land and cropland } \\
\text { encroach on water body }\end{array}$ & $\begin{array}{c}\text { Convert cropland to water bodies and expand the } \\
\text { water surface area; } \\
\text { Engage in greening to enhance the opportunities } \\
\text { for recreation and leisure. }\end{array}$ \\
\hline Bundle 5 & Built-up land & $\begin{array}{l}\text { Built-up land encroaches on } \\
\text { other ecological space }\end{array}$ & $\begin{array}{c}\text { Build ecological corridors, small urban green } \\
\text { spaces, diversified natural ecological spaces; } \\
\text { Enhance the urban ecological space's outdoor } \\
\text { leisure capacity. }\end{array}$ \\
\hline
\end{tabular}




\section{Discussion}

Our work began by acknowledging the necessary trade-off of multiple needs, identifying the priority ecological restoration areas with hotspots of ecological quality and health, and conducting a cluster analysis of urban agglomerations in township administrative units by machine learning. Our work provides a new method to identify and rank the management of ecological restoration areas scientifically. Previous studies have assessed ecological space largely from a single perspective and focused on its spatial and temporal distribution, as well as changes in ecological risk $[8,44]$. Previous studies have given more attention to the function of ecological space, including physical and biological composition and its benefits. Further, the research scale in the studies has been small (e.g., landscape, community scale), which may not capture the true magnitude of the damage that biodiversity and ecosystem functions and services have suffered, such that the application of the data to urban planning and policymaking had limitations [14]. Few studies have addressed the combination of ecological policy and ecological restoration areas' identification [45]. In China, ecological restoration is led primarily by the government, which is concerned principally with the construction of regional-scale ecological security, and has insisted that a holistic approach to protecting and restoring mountains, rivers, forests, croplands, lakes, and grasslands is necessary. Based upon this concept, our research filled a knowledge gap between ecological management, restoration, and assessment, which was based upon stakeholders' general concerns, policymakers' policy goals, and the public's needs. Our results may help policymakers formulate ecological policy and implement urban planning. The methods of this study will help reveal the public preferences on ecological space under urbanization in urban agglomeration. Our model can be applied to many scales, including county, city, urban agglomeration, province, and country. Through the spatial pattern distribution, we can explore their differences and internal relations, comprehensively analyze the results of ecological restoration spatial identification at different scales, and explore their internal correlations, as well as the ways and methods of mutual conversion between different scales. However, for some small scales, such as landscape patches, because the landscape evaluation index is focused on structure and function evaluation, this model cannot objectively reflect the actual results. The index system of this study can provide an initial choice for other urban agglomerations. However, the local actual situation should be considered, then establish the index system to suit local characteristics.

The combination of ecological quality and ecological health is an ideal endpoint in identifying ecological restoration areas. Considerable previous research had assessed ecological quality and health. However, there was still no way to assess ecological space comprehensively to identify ecological restoration areas. Hence, this study adopted the vigor-organization-resilience system assessment framework to assess ecological health based upon previous studies $[25,46]$. However, in selecting resilience indicators, this study did not adopt area-weighted ecosystem resilience coefficients to calculate land-use types; rather, we adopted the ecosystem services indicators with which policymakers and stakeholders are concerned generally. Existing studies had incorporated ecosystem services into the assessment of ecological health risk [25], as these have always been important indicators of ecological health from the human-nature coupled view [47]. Land use changes affect the ecosystem itself primarily through the services it provides, so the assessment of ecosystem services reflects the ecosystems' flexibility and sustainability better. Ecological quality and health and ecosystem services may be considered to have a reciprocal causal relation, which was an appropriate medium to evaluate ecological space comprehensively on the regional scale.

Ecological zoning is the core method of regional ecological management [48], and it has been recognized that the classification of ecological restoration areas through scientific and adaptive evaluation methods is one of policymakers' common concerns. Particularly for urban agglomerations, different cities' development level and ecological goals differ, and the failure to identify ecological zoning from the perspective of urban agglomerations has led to confusion and inconsistent management. Further, the mismatch between 
ecological restoration areas and administrative boundaries has led to the formulation of irrational policy and control implementation [5,49]. Based upon the assessment indicators of ecological quality and ecological health, this study used machine learning to classify the township scale according to the ecological restoration area's characteristics. The bundle could classify towns with similar ecological conditions clearly, identify ecological shortcomings in towns, and provide a further theoretical basis for policymakers to formulate ecological management policies on the urban agglomeration scale [17,40,50].

Our case study also had some limitations. Firstly, the research framework serves only as a stage in delineating the priority ecological restoration area. To determine the final ecological restoration area, policymakers need to consider more socioeconomic factors, particularly the interests of stakeholders in the restoration area. This research provided the basic framework with which to identify the priority ecological restoration area. Secondly, to determine the hotspot area's threshold, this study considered the scale of the PRD urban agglomeration, and combined the experts' knowledge and policy targets. Thus, the threshold was based upon a multiparty trade-off and societally-informed choice. However, the hotspot area's threshold may be updated over time depending upon socioeconomic development or the development of more advanced technology, and may generally vary in another region. Thirdly, although our cluster analysis divided the urban agglomeration into five bundles, the basis of classification was primarily the ecological indicators. Hence, the analysis of the bundles' determining socioeconomic forces is still incomplete. The zoning management of ecological restoration areas should be the focus of future research on socioeconomic determinants. Establish a suitable local spatial clustering method focused on social economy and natural factors may be a way for future additional investigations of ecological restoration to meet the complex and changeable urban ecosystem.

\section{Conclusions}

Based upon policy goals and public preferences, this study proposed a comprehensive method to identify priority ecological restoration areas by integrating the ecological space's quality and health, and performing a cluster analysis of a township using machine learning. In this way, we produced useful insights about the influence of policy decisions or actions to define ecological restoration areas at the scale of urban agglomeration, as well as basic assumptions for urban planning and ecological management. This study found that the priority restoration areas were distributed primarily in the areas surrounding built-up urban areas. This can be explained in part by the current state of the urbanization, urbanized for many years without real consideration of the regional ecological quality and ecological health, reinforced by the global context of the urbanization expansion. Thus, identification of ecological restoration areas requires a strong and assumed multi-actors governance in favor of improving ecological quality and ecological health facing past and future urbanization pressures. To achieve this, we still need to develop frameworks outlining core socioecological criteria for determining ecological restoration targets. We need clear illustrations of the main methodological steps for identifying ecological restoration areas to communicate the importance of different socio-ecological components to stakeholders. The next step is to develop society-economic-nature index datasets to link ecosystem characteristics and socioeconomic characteristics to evaluate the socio-ecological outcomes from the multiple trade-offs to refine actual ecological restoration on the ground. Future ecological restoration should be unified planning according to the multiple trade-offs with the development trend of urbanization degree and should strengthen the restoration and construction of ecological space intra-city built-up area. It can be concluded that this approach permitted to fill a gap in the identity of ecological restoration in the spheres of science and policy interdependencies, with the aim of the consideration of ecological quality and ecological health in urban agglomeration ecological management.

Supplementary Materials: The following are available online at https:/ /www.mdpi.com/article/10 $.3390 /$ rs13122424/s1, Figure S1. The public preference of ecological space quality. Table S1. The error matrix of classified and reference data for 2018. Table S2. Attributes of respondents. Table S3. Weight 
of land use types of biodiversity index. Table S4. Weight of the outdoor recreation index. Table S5. Weight of the land fragile index.

Author Contributions: Conceptualization, X.C. and F.L.; data curation, X.C., X.L., Y.H. and P.H.; formal analysis, X.C., X.L. and H.L.; funding acquisition, F.L.; methodology, X.C.; writing-original draft, X.C.; writing-review and editing, X.C., F.L., X.L. and H.L. All authors have read and agreed to the published version of the manuscript.

Funding: This research was funded by the Key project of the National Natural Science Foundation of China [No. 71734006] and the National Key Research and Development Program of China [No. 2016YFC0502800].

Data Availability Statement: The data presented in this study are available on request from the corresponding author.

Acknowledgments: The authors would like to thank all reviewers and editors for their comments on this paper.

Conflicts of Interest: The authors declare no conflict of interest.

\section{References}

1. Song, X.; Hansen, M.; Stehman, S.; Potapov, P.; Tyukavina, A.; Vermote, E.; Townshend, J. Global land change from 1982 to 2016. Nature 2018, 560, 639-643. [CrossRef]

2. Kalnay, E.; Cai, M. Impact of urbanization and land-use change on climate. Nature 2003, 423, 528. [CrossRef]

3. Zhang, Y.; Liu, Y.; Zhang, Y.; Liu, Y.; Zhang, G.; Chen, Y. On the spatial relationship between ecosystem services and urbanization: A case study in Wuhan, China. Sci. Total Environ. 2018, 637-638, 780-790. [CrossRef] [PubMed]

4. Zagonari, F. Using ecosystem services in decision-making to support sustainable development: Critiques, model development, a case study, and perspectives. Sci. Total Environ. 2016, 548, 25-32. [CrossRef]

5. DeFries, R.; Nagendra, H. Ecosystem management as a wicked problem. Science 2017, 356, 265-270. [CrossRef] [PubMed]

6. Ren, Y.; Lu, Y.; Fu, B.; Comber, A.J.; Li, T.; Hu, J. Driving Factors of Land Change in China's Loess Plateau: Quantification Using Geographically Weighted Regression and Management Implications. Remote Sens. 2020, 12, 453. [CrossRef]

7. Hu, M.; Li, Z.; Wang, Y.; Jiao, M.; Li, M.; Xia, B. Spatio-temporal changes in ecosystem service value in response to land-use/cover changes in the Pearl River Delta. Resour. Conserv. Recy. 2019, 149, 106-114. [CrossRef]

8. Baró, F.; Gomez-Baggethun, E.; Haase, D. Ecosystem service bundles along the urban-rural gradient: Insights for landscape planning and management. Ecosyst. Serv. 2017, 24, 147-159. [CrossRef]

9. Burkhard, B.; Kroll, F.; Nedkov, S.; Müller, F. Mapping ecosystem service supply, demand and budgets. Ecol. Indicat. 2012, 21, 17-29. [CrossRef]

10. Jiao, M.; Hu, M.; Xia, B. Spatiotemporal dynamic simulation of land-use and landscape-pattern in the Pearl River Delta, China. Sustain. Cities Soc. 2019, 49, 101581. [CrossRef]

11. Dick, J.; Turkelboom, F.; Woods, H.; Iniesta-Arandia, I.; Primmer, E.; Saarela, S.-R.; Bezák, P.; Mederly, P.; Leone, M.; Verheyden, W. Stakeholders' perspectives on the operationalisation of the ecosystem service concept: Results from 27 case studies. Ecosyst. Serv. 2018, 29, 552-565. [CrossRef]

12. Luo, Y.; Lü, Y.; Fu, B.; Zhang, Q.; Li, T.; Hu, W.; Comber, A. Half century change of interactions among ecosystem services driven by ecological restoration: Quantification and policy implications at a watershed scale in the Chinese Loess Plateau. Sci. Total Environ. 2019, 651, 2546-2557. [CrossRef]

13. Chen, X.; Li, F.; Li, X.; Hu, Y.; Wang, Y. Mapping ecological space quality changes for ecological management: A case study in the Pearl River Delta urban agglomeration, China. J. Environ. Manag. 2020, 267, 110658. [CrossRef]

14. Bai, Y.; Wong, C.; Jiang, B.; Hughes, A.; Wang, M.; Wang, Q. Developing China's Ecological Redline Policy using ecosystem services assessments for land use planning. Nat. Commun. 2018, 9, 3034. [CrossRef]

15. Xu, X.; Yang, G.; Tan, Y. Identifying ecological red lines in China's Yangtze River Economic Belt: A regional approach. Ecol. Indic. 2019, 96, 635-646. [CrossRef]

16. Bennett, E.M.; Peterson, G.D.; Gordon, L.J. Understanding relationships among multiple ecosystem services. Ecol. Lett. 2009, 12, 1394-1404. [CrossRef] [PubMed]

17. Schirpke, U.; Candiago, S.; Egarter Vigl, L.; Jager, H.; Labadini, A.; Marsoner, T.; Meisch, C.; Tasser, E.; Tappeiner, U. Integrating supply, flow and demand to enhance the understanding of interactions among multiple ecosystem services. Sci. Total Environ. 2019, 651, 928-941. [CrossRef] [PubMed]

18. Peng, J.; Liu, Y.; Wu, J.; Lv, H.; Hu, X. Linking ecosystem services and landscape patterns to assess urban ecosystem health: A case study in Shenzhen City, China. Landscape Urban Plann. 2015, 143, 56-68. [CrossRef]

19. Spangenberg, J.H.; Görg, C.; Settele, J. Stakeholder involvement in ESS research and governance: Between conceptual ambition and practical experiences-risks, challenges and tested tools. Ecosyst. Serv. 2015, 16, 201-211. [CrossRef] 
20. Wilker, J.; Rusche, K.; Benning, A.; MacDonald, M.A.; Blaen, P. Applying ecosystem benefit valuation to inform quarry restoration planning. Ecosyst. Serv. 2016, 20, 44-55. [CrossRef]

21. Baker, S.; Eckerberg, K. A policy analysis perspective on ecological restoration. Ecol. Soc. 2013, 18, 17. [CrossRef]

22. del Río-Mena, T.; Willemen, L.; Tesfamariam, G.T.; Beukes, O.; Nelson, A. Remote sensing for mapping ecosystem services to support evaluation of ecological restoration interventions in an arid landscape. Ecol. Indic. 2020, 113, 106182. [CrossRef]

23. Nguyen, K.-A.; Liou, Y.-A. Global mapping of eco-environmental vulnerability from human and nature disturbances. Sci. Total Environ. 2019, 664, 995-1004. [CrossRef]

24. Trabucchi, M.; O’Farrell, P.J.; Notivol, E.; Comín, F.A. Mapping ecological processes and ecosystem services for prioritizing restoration efforts in a semi-arid Mediterranean river basin. Environ. Manag. 2014, 53, 1132-1145. [CrossRef]

25. Kang, P.; Chen, W.; Hou, Y.; Li, Y. Linking ecosystem services and ecosystem health to ecological risk assessment: A case study of the Beijing-Tianjin-Hebei urban agglomeration. Sci. Total Environ. 2018, 636, 1442-1454. [CrossRef]

26. Tao, Y.; Wang, H.; Ou, W.; Guo, J. A land-cover-based approach to assessing ecosystem services supply and demand dynamics in the rapidly urbanizing Yangtze River Delta region. Land Use Pol. 2018, 72, 250-258. [CrossRef]

27. Chen, X.; Li, F.; Li, X.; Hu, Y.; Hu, P. Quantifying the Compound Factors of Forest Land Changes in the Pearl River Delta, China. Remote Sens. 2021, 13, 1911. [CrossRef]

28. Wang, R.; Li, F.; Hu, D.; Li, B. Understanding eco-complexity: Social-economic-natural complex ecosystem approach. Ecol. Complex. 2011, 8, 15-29. [CrossRef]

29. Ngom, R.; Gosselin, P.; Blais, C. Reduction of disparities in access to green spaces: Their geographic insertion and recreational functions matter. Appl. Geogr. 2016, 66, 35-51. [CrossRef]

30. Wang, P.; Lassoie, J.P.; Morreale, S.J.; Dong, S. A critical review of socioeconomic and natural factors in ecological degradation on the Qinghai-Tibetan Plateau, China. Rangel. J. 2015, 37, 1-9. [CrossRef]

31. Shen, G.; Yang, X.; Jin, Y.; Xu, B.; Zhou, Q. Remote sensing and evaluation of the wetland ecological degradation process of the Zoige Plateau Wetland in China. Ecol. Indic. 2019, 104, 48-58. [CrossRef]

32. Peng, J.; Pan, Y.; Liu, Y.; Zhao, H.; Wang, Y. Linking ecological degradation risk to identify ecological security patterns in a rapidly urbanizing landscape. Habitat Int. 2018, 71, 110-124. [CrossRef]

33. Sahraoui, Y.; Leski, C.D.G.; Benot, M.-L.; Revers, F.; Salles, D.; van Halder, I.; Barneix, M.; Carassou, L. Integrating ecological networks modelling in a participatory approach for assessing impacts of planning scenarios on landscape connectivity. Landsc. Urban Plan. 2021, 209, 104039. [CrossRef]

34. Wyant, J.G.; Meganck, R.A.; Ham, S.H. A planning and decision-making framework for ecological restoration. Environ. Manag. 1995, 19, 789-796. [CrossRef]

35. Liu, X.; Liu, L.; Peng, Y. Ecological zoning for regional sustainable development using an integrated modeling approach in the Bohai Rim, China. Ecol. Modell. 2017, 353, 158-166. [CrossRef]

36. Baró, F.; Palomo, I.; Zulian, G.; Vizcaino, P.; Haase, D.; Gomez-Baggethun, E. Mapping ecosystem service capacity, flow and demand for landscape and urban planning: A case study in the Barcelona metropolitan region. Land Use Pol. 2016, 57, 405-417. [CrossRef]

37. Tian, G.; Qiao, Z. Assessing the impact of the urbanization process on net primary productivity in China in 1989-2000. Environ. Pollut. 2014, 184, 320-326. [CrossRef]

38. Colding, J. 'Ecological land-use complementation'for building resilience in urban ecosystems. Landsc. Urban Plan. 2007, 81, 46-55. [CrossRef]

39. Fu, B.; Xu, P.; Wang, Y.; Yan, K.; Chaudhary, S. Assessment of the ecosystem services provided by ponds in hilly areas. Sci. Total Environ. 2018, 642, 979-987. [CrossRef]

40. Spake, R.; Lasseur, R.; Crouzat, E.; Bullock, J.M.; Lavorel, S.; Parks, K.E.; Schaafsma, M.; Bennett, E.M.; Maes, J.; Mulligan, M. Unpacking ecosystem service bundles: Towards predictive mapping of synergies and trade-offs between ecosystem services. Environ. Chang. 2017, 47, 37-50. [CrossRef]

41. Liu, Y.; Lu, Y.; Fu, B.; Harris, P.; Wu, L. Quantifying the spatio-temporal drivers of planned vegetation restoration on ecosystem services at a regional scale. Sci. Total Environ. 2019, 650, 1029-1040. [CrossRef]

42. Mass, E.; Ballesteros, I.; Farlik, M.; Halbritter, F.; Günther, P.; Crozet, L.; Jacome-Galarza, C.E.; Händler, K.; Klughammer, J.; Kobayashi, Y. Specification of tissue-resident macrophages during organogenesis. Science 2016, 353, aaf4238. [CrossRef] [PubMed]

43. Xu, X.; Jiang, B.; Chen, M.; Bai, Y.; Yang, G. Strengthening the effectiveness of nature reserves in representing ecosystem services: The Yangtze River Economic Belt in China. Land Use Pol. 2020, 96, 104717. [CrossRef]

44. Bryan, B.A.; Ye, Y.; Connor, J.D. Land-use change impacts on ecosystem services value: Incorporating the scarcity effects of supply and demand dynamics. Ecosyst. Serv. 2018, 32, 144-157. [CrossRef]

45. Linkov, I.; Satterstrom, F.K.; Kiker, G.; Batchelor, C.; Bridges, T.; Ferguson, E. From comparative risk assessment to multi-criteria decision analysis and adaptive management: Recent developments and applications. Environ. Int. 2006, 32, 1072-1093. [CrossRef] [PubMed]

46. Peng, J.; Tian, L.; Liu, Y.; Zhao, M.; Hu, Y.; Wu, J. Ecosystem services response to urbanization in metropolitan areas: Thresholds identification. Sci. Total Environ. 2017, 607, 706-714. [CrossRef] 
47. Bateman, I.J.; Harwood, A.R.; Mace, G.M.; Watson, R.T.; Abson, D.J.; Andrews, B.; Binner, A.; Crowe, A.; Day, B.H.; Dugdale, S.J.S. Bringing ecosystem services into economic decision-making: Land use in the United Kingdom. Science 2013, 341, 45-50. [CrossRef]

48. De Groot, R.S.; Alkemade, R.; Braat, L.; Hein, L.; Willemen, L. Challenges in integrating the concept of ecosystem services and values in landscape planning, management and decision making. Ecol. Complex. 2010, 7, 260-272. [CrossRef]

49. Dey, D.C.; Schweitzer, C.J. Restoration for the future: Endpoints, targets, and indicators of progress and success. J. Sustain. For. 2014, 33, S43-S65. [CrossRef]

50. Burkhard, B.; Kandziora, M.; Hou, Y.; Müller, F. Ecosystem Service Potentials, Flows and Demands-Concepts for Spatial Localisation, Indication and Quantification. Landsc. Online 2014, 34, 1-32. [CrossRef] 